\title{
SISTEM MANAJEMEN INVENTORI KOMPUTER MENGGUNAKAN NEAR FIELD COMMUNICATION BERBASIS ANDROID (STUDI KASUS DI STIE PELITA INDONESIA PEKANBARU)
}

\section{COMPUTER INVENTORY MANAGEMENT SYSTEM USING NEAR FIELD COMMUNICATION BASED ANDROID (CASE STUDY IN STIE PELITA INDONESIA PEKANBARU)}

\author{
Muhammad Luhtfi Hamzah ${ }^{1}$ dan Astri Ayu Purwati ${ }^{2}$ \\ STIKOM Pelita Indonesia ${ }^{1}$, STIE Pelita Indonesia ${ }^{2}$ \\ astri.ayu@lecturer.pelitaindonesia.ac.id ${ }^{1}$, \\ luthfi.hamzah@lecturer.pelitaindonesia.ac.id ${ }^{2}$
}

\begin{abstract}
Higher education is an institution that is heavily influenced by technological advances, especially in the field of computer technology. The purpose of this study is to create a computer inventory management system in higher education which is previously using manuals system become technology-based system in order to work more effective and efficient. The research method used is design of inventory tracking system application using NFC android based. The results showed that by using Inventory Tracking System's model is more effective and efficient to identify any inventory information in the computer lab STIE Pelita Indonesia
\end{abstract}

Keywords : Inventory Tracking, RFID, Near Field Communication, NFC.

\begin{abstract}
ABSTRAK
Perguruan tinggi merupakan suatu lembaga yang sangat dipengaruhi oleh kemajuan teknologi terutama di bidang teknologi komputer. Tujuan dari penelitian ini adalah untuk membuat sistem pengelolaan inventori komputer pada perguruan tinggi yang sebelumnya manual menjadi berbasis teknologi agar hasil kerja lebih efektif dan efisien. Metode penelitian yang digunakan adalah perancangan aplikasi inventory tracking system dengan menggunakan NFC berbasis android. Hasil penelitian menunjukkan dengan menggunakan pemodelan Sistem Pelacakan Inventory lebih efektif dan efisien dalam mengidentifikasi informasi setiap inventory laboratorium komputer di STIE Pelita Indonesia.
\end{abstract}

Kata Kunci : Inventory Tracking, RFID, Near Field Communication, NFC.

\section{PENDAHULUAN}

Manajemen inventory merupakan suatu usaha memonitor dan menentukan tingkat komposisi bahan yang optimal dalam menunjang kelancaran dan efektifitas serta efisiensi dalam kegiatan perusahaan.Oleh karena itu, desngan berkembangnya teknologi, maka manajemen inventory yang baik merupakan hal yang penting bagi setiap perusahaan dalam melaksanakan kegiatannya. Sistem pelacakan inventory adalah sistem yang didesain untuk memantau pergerakan inventory. Salah satu sistem pelacakan inventory yang umum digunakan adalah RFID 
(Radio frequency identification) yang merupakan sebuah sistem identifikasi frekuensi radio menggunakan tag, atau label yang melekat pada objek yang akan diidentifikasi. Teknologi terbaru dari RFID adalah Near Field Communication (NFC) karena NFC merupakan subset dari RFID yang mana teknologi ini mampu menyederhanakan transaksi, pertukaran data, dan koneksi nirkabel antar dua perangkat komunikasi dengan jarak amat dekat (hanya beberapa sentimeter) dengan prinsip induksi medan magnetic (Trivedi D., 2015).

Sangatlah sulit untuk membayangkan kehidupan modern tanpa komputer. Selain itu, ia adalah mustahil untuk berfikir tentang kantor, perusahaan dan proses kegiatan bisnis tanpa mesin ini. Kemajuan teknologi masa sekarang menuntut seluruh organisasi untuk dapat mengaplikasikan perkembangan teknologi tersebut ke dalam organisasi agar mampu bersaing secara nasional maupun global. Salah satu organisasi yang paling mengalami dampak dari perkembangan teknologi adalah dunia pendidikan. Perguruan tinggi merupakan suatu lembaga yang sangat dipengaruhi oleh kemajuan teknologi terutama di bidang teknologi komputer. Semua aspek kegiatan akademik pada perguruan tinggi seperti belajar mengajar, administrasi dan lainnya di era modern ini sudah pasti menggunakan perangkat komputer. Hal tersebut dikarenakan bagi menjadikan semua proses akademik dapat berjalan lebih efektif dan efisien dengan peralihan dari sistem manual menuju sistem berbasis teknologi. Dikarenakan komputer merupakan salah satu aset penting di perguruan tinggi terutama di STIE (Sekolah Tinggi Ilmu Ekonomi) Pelita Indonesia dalam menunjang kualitas akademik, maka di anggap perlu adanya sebuah sistem yang dapat mengelola komputer-komputer pada perguruan tinggi tersebut terutama sistem pelacakan inventory yang berbasis teknologi seperti RFID/NFC.

Inventory merupakan salah satu masalah yang sangat penting yang sangat fundamental dalam setiap perusahaan. Karena inventory merupakan salah satu faktor dalam menentukan kelancaran produksi dan penjualan, maka penting adanya pengelolaan inventory secara tepat. Manajemen inventory merupakan proses mengelola pengadaan atau persediaan barang yang dimiliki oleh suatu kantor atau perusahaan dalam melakukan kegiatan operasionalnya, tanpa adanya inventory suatu kegiatan usaha tidak akan terlaksana, untuk itu keberadaan inventory sangat penting.

Inventory merupakan simpanan barang-barang mentah, material atau barang jadi yang disimpan untuk digunakan dalam masa mendatang atau dalam kurun waktu tertentu. Persediaan barang sangat penting dalam suatu perusahaan dalam menghadapi perubahan pasar produksi serta mengantisipasi perubahan harga dalam permintaan barang yang banyak. Inventory adalah sejumlah sumber daya baik berbentuk bahan mentah ataupun barang jadi yang disediakan perusahaan untuk memenuhi permintaan dari konsumen. Sedangkan pengertian inventory dalam definisi lainnya adalah suatu teknik untuk manajemen material yang berkaitan dengan persediaan (Heryanto A., Fuad H. dan Dananggi D., 2014).

Manajemen adalah proses pengoordinasian kegiatan-kegiatan pekerjaan sehingga pekerjaan tersebut terselesaikan secara efisien dan efektif dengan dan melalui orang lain. Efisiensi mengacu pada memperoleh output terbesar dengan input terkecil digambarkan sebagai melakukan segala 
sesuatu secara benar. Sedangkan efektivitas mengacu pada menyelesaikan kegiatan-kegiatan sehingga sasaran organisasi dapat tercapai, digambarkan sebagai melakukan segala sesuatu yang benar (Robbins S.dan Coulter M., 2007). Manajemen adalah serangkaian aktivitas manusia yang berkesinambungan dalam mencapai suatu tujuan yang telah ditetapkannya (Heene A. dan Desmidt S., 2010).

Smartphone sudah tidak asing lagi bagi pengguna telepon seluler, smartphone adalah telepon genggam yang mempunyai kemampuan tingkat tinggi, terkadang dengan fungsi yang menyerupai komputer. Android adalah sistem operasi yang berbasis Linux untuk telepon seluler seperti telepon pintar dan komputer tablet. Android menyediakan platform terbuka bagi para pengembang untuk menciptakan aplikasi mereka sendiri untuk digunakan oleh bermacam peranti bergerak. Perkembangan media teknologi informasi dan komunikasi pada era sekarang ini menunjukan betapa semakin banyak media komunikasi yang beredar dalam masyarakat. Hal ini dikarenakan sangat banyak inovasi dan metamorphosis dari pada media komunikasi yang sedang mewabah dalam masyarakat sekarang ini. Salah satu contoh yang bisa kita lihat adalah masyarakat cenderung menggunakan telepon genggam untuk menjadi media komunikasi antara satu orang kepada orang lain yangberada di tempat lain. Kenyataan telah menjadi sebuah fenomena yang sudah lazim ditengah masyarakat dunia. Namun tidak hanya sampai disitu hal lain yang menjadi perhatian adalah yang mana bersama berjalannya waktu telepon genggam yang sering digunakan sudah berinovasi menjadi telepon pintar "smartphone". Masyarakat sekarang beramai-ramai menggunakan berbagai jenis smarphone khususnya android. Hal itu seturut dengan kemampuan, motivasi, keinginan serta kebutuhan masyarakat terhadap kegunaan dari pada media tersebut (Juraman S. R., 2014).

RFID merupakan salah satu teknologi dari sistem pengindentifikasian suatu objek secara otomatis (Auto ID) selain barcode Optical Character Recognition (OCR), biometric, dan Smartcard. Berbagai macam pengindentifikasian tersebut telah banyak membantu dalam berbagai bidang pengidentifikasian objek yang dapat dikembangkan dan diterapkan untuk pemerintahan, rumah sakit, sekolah, universitas, institusi penilitian dan laboratorium, penerbangan, paspor, perniagaan, transportasi, gerbang jalan tol, museum, pergudangan, perpustakaan, parkir, dan lain-lain (Finkenzeller K., 2003).

Teknologi NFC sekarang banyak ditemukan di beberapa smartphone terbaru yang dilengkapi dengan teknologi NFC (Near Field Communication). Teknologi NFC ini merupakan kesinambungan teknologi dari RFID dan bluetooth, karena kalau diperhatikan dengan baik teknologi yang ada di dalam RFID dan bluetooth itu ada di teknologi NFC. NFC adalah teknologi wireless yang memiliki frekuensi tinggi $(13.56 \mathrm{MHz})$ yang memiliki kecepatan transfer data 424 Kbits/second dengan jarak jangkauan yang pendek atau dekat. Alat ini dapat dipergunakan untuk pertukaran data dengan jarak sekitar $10 \mathrm{~cm}$. Teknologi NFC merupakan gabungan antara smartcard dan smartcard reader yang ditanam di dalam satu perangkat, umumnya perangkat tersebut merupakan perangkat mobile seperti telepon genggam. Dengan adanya perangkat NFC yang ditanam di dalam sebuah perangkat mobile seperti telepon 
genggam, maka kegiatan transaksi seperti pembayaran atau transaksi micro payment dapat dilakukan dengan mendekatkan perangkat NFC ini ke perangkat NFC, smartcard atau smartcard reader yang berada di point of sales transaksi tersebut. Dengan adanya fitur seperti ini maka NFC disebut sebagai perangkat yang mendukung "contactless transaction" (Rismawati N., 2016).

Near Field Communication (NFC) adalah sebuah spesifikasi untuk komunikasi contactless antara dua perangkat.NFC didasarkan pada teknologi yang digunakan untuk RFID dan standar dalam ISO / IEC 18092. Hal ini terbatas pada jarak antara kedua perangkat hingga $10 \mathrm{~cm}$. NFC ini dimaksudkan untuk memudahkan dan lebih nyaman untuk melakukan transaksi, pertukaran konten digital, dan menghubungkan perangkat elektronik dengan sentuhan (NFC Forum, 2016). NFC memungkinkan komunikasi dua arah antara perangkat elektronik dan memiliki kemampuan untuk menulis ke RFID (Radio Frequency Identification) Chip. Oleh karena itu komunikasi dua arah antara ponsel NFC dilengkapi dan NFC reader dapat dibentuk yang membuat kemungkinan untuk mengembangkan aplikasi yang kompleks seperti pembayaran, pertukaran data secara aman dan otentikasi identitas ini. NFC menerapkan paradigma menyentuhyaitu metode terkenal dan interaktif dalam kehidupan manusia. Hal ini membuat teknologi NFC mudah dipelajari dan digunakan. Paradigma yang menyentuh ini awalnya digunakan dalam RFID (Radio Frequency Identification) teknologi. Dalam RFID item teknologi ditandai dengan tag berisi transponder yang memancarkan pesan dalam bentuk sinyal pembaca RFID digunakan untuk membaca pesan tersebut. NFC sekarang terintegrasi dengan teknologi RFID ini (O'Neill E., Thompson P., Garzonis S. andWarr A., 2007).

\section{METODE PENELITIAN}

Adapun alur metode penelitian yang digunakan adalah sebagai berikut :

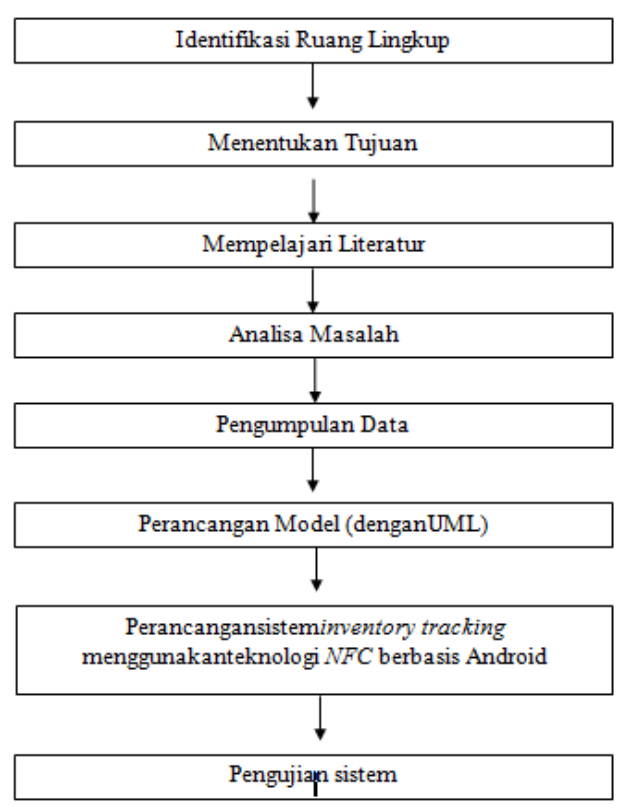

Gambar 1. Alur penelitian

Penelitian akan dilakukan berdasarkan urutan dari kerangka kerja di atas. Berikut penjelasansecara detail kerangka kerja penelitian gambar 1 di atas.

1. Identifikasi Ruang Lingkup. Pada tahap ini penulis melakukan identifikasi terhadap ruang lingkup penelitian yang bertujuan untuk menjaga konsistensi dari penelitian ini sehingga penelitian ini lebih terarah dan tercapinya tujuan dari penelitian yang diharapkan. Dalam mengidentifikasi ruang lingkup ini penulis menetapkan batasan masalah yang akan dipecahkan. Dalam hal ini berupa pemodelan UML untuk perancangan sistem inventory tracking menggunakan teknologi NFC berbasis 
Android.

2. Menentukan Tujuan. setelah membatasi ruang lingkup dan perumusan masalah dalam topik yang diteliti, tahap selanjutnya yaitu menentukan kerangka tujuan terhadap penelitian yang dilakaukan.Di mana tujuan dari penelitian ini adalah bagaimana merancang model UML untuk untuk perancangan sisteminventory tracking menggunakan teknologi NFC berbasis Android.

3. Mempelajari Literatur. Langkah selanjutnya adalah mempelajari literatur-literatur agar dapat diseleksi untuk dapat ditentukan literatur mana yang akandigunakan dalam penelitian ini. Sumber literatur didapatkan dari jurnal, artikel, yang membahas tentang inventory management, inventory tracking system, smartphone, Android, NFC terutama inventory management dengan NFC pada smartphone Android dan bahan bacaan lain yang mendukung penelitian.

4. Analisa Masalah Analisa masalah dilakukan untuk dapat memahami masalah yang telah ditemukan pada penelitian lapangan. Dengan menganalisa masalah tersebut, maka diharapkan masalah dapatdipahami dengan baik sehingga dapat ditentukan langkah penyelesaiannya. Masalah yang dimaksud adalah bagaimana merancang dan membangun sebuah aplikasi android untuk melakukan tracking terhadap inventory komputer laboratorium.

5. Pengumpulan Data, Setelah menganalisa masalah, maka langkah selanjutnya adalah mengumpulkan datadata yang diperlukan untuk pembuatan rancang bangun sistem inventory tracking dengan menggunakan teknologi NFC berbasis Android.

6. Perancangan Model. Setelah didapatkan analisa terhadap masalah dilakukan. Langkah selanjutnya yaitu menuangkan permasalahan tersebut ke dalam bentuk model UML. Model UML nantinya akan dipergunakan lebih lanjut dalam membangun aplikasi inventory tracking system dengan menggunakan NFC berbasis android.

7. Perancangan Sistem. Hasil dari perancangan model diatas selanjutnya akan diimplementasikan ke dalam perancangan sistem inventory. Dalam hal ini, sistem yang dimaksud adalah aplikasi pembelajaran berbasis android. Perancangan ini nantinya akan dibuat sesuai dengan menggunakan teknologi NFC pada android menggunakan bahasa JAVA dengan bantuan software Eclipse, Macromedia Dreamweaver, PHP dan Mysql, sehinggaaplikasi ini bisaberjalan lancar di smartphone berbasis android.

8. Pengujian Sistem Sistem yang telah dirancang di atas selanjutnya diuji untuk melihat sejauh mana sistem yang dibangun telah sesuai dengan yang diharapakan.

HASIL DAN PEMBAHASAN

1. Perancangan model

Use Case Diagram

Use case menggambarkan

bagaimana seseorang akan menggunakan atau memanfaatkan sistem atau aplikasi yang menggambarkan proses-proses yang dilakukan oleh pengguna terhadap sistem atau aplikasi. berikut aplikasi penggunaan dari sistem manajemen inventori komputer yang telah dihasilkan :

Berikut pula dijelaskan definisi dari use case diagram di atas : 


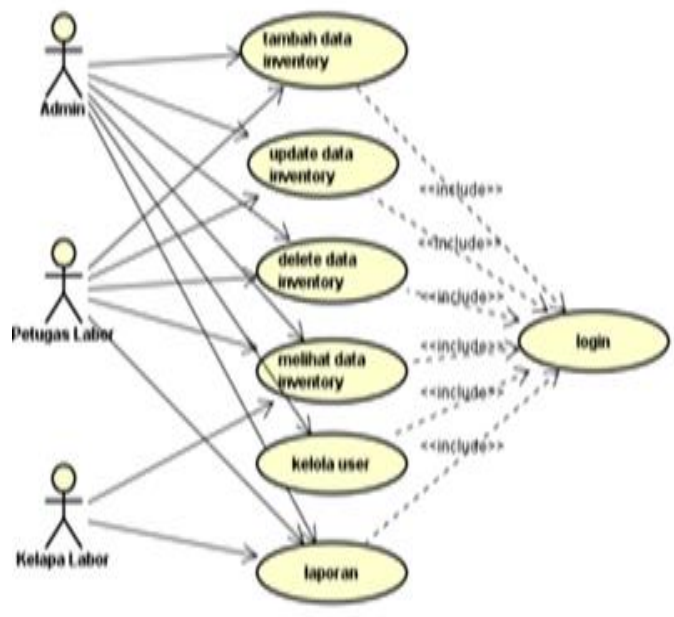

Gambar 2. Use Case Diagram

Tabel 1 Definisi Dalam Use Case

Diagram Sistem Pelacakan Inventory Menggunakan Teknologi NFC

\begin{tabular}{|c|c|c|}
\hline No & Use Case & Deskripsi \\
\hline 1. & $\begin{array}{l}\text { Melakukan } \\
\text { login }\end{array}$ & $\begin{array}{l}\text { User dapat melakukan login } \\
\text { terlebih dahulu sebelum } \\
\text { masuk ke sistem }\end{array}$ \\
\hline 2. & $\begin{array}{l}\text { Tambah data } \\
\text { inventory } \\
\text { dengan } \\
\text { teknologi NFC }\end{array}$ & \begin{tabular}{lr} 
Admin dan & Petugas \\
laboratorium menambahkan \\
data inventory pada setiap \\
komputer & \multicolumn{2}{c}{ dengan } \\
menempelkan smartphone \\
android ke NFC tag
\end{tabular} \\
\hline 3 & $\begin{array}{l}\text { update data } \\
\text { inventory } \\
\text { dengan } \\
\text { menggunakan } \\
\text { NFC }\end{array}$ & $\begin{array}{l}\text { Admin dan Petugas } \\
\text { melakukan update data pada } \\
\text { setiap komputer dengan } \\
\text { menempelkan smartphone ke } \\
\text { NFC tag terlebih dahulu } \\
\text { kemudian smartphone } \\
\text { membaca NFC tag tersebut. }\end{array}$ \\
\hline 4. & $\begin{array}{ll}\text { Delete data } \\
\text { inventory }\end{array}$ & $\begin{array}{l}\text { Admin dan Petugas dapat } \\
\text { menghapus data inventory } \\
\text { pada NFC tag dan Database }\end{array}$ \\
\hline 5. & $\begin{array}{l}\text { MelihatDataInv } \\
\text { entory }\end{array}$ & $\begin{array}{l}\text { Admin, Petugas dan Kepala } \\
\text { Laboratorium dapat melihat } \\
\text { data di setiap tag dan di } \\
\text { website }\end{array}$ \\
\hline 6. & Laporan & $\begin{array}{l}\text { Kepala Labor dan Admin } \\
\text { dapat hasil laporan } \\
\text { keseluruhan } \\
\text { komputer di website sistem } \\
\text { pelacakan inventory }\end{array}$ \\
\hline 7. & Kelola User & $\begin{array}{l}\text { Admin dapat melakukan add, } \\
\text { edit, delete user pada sistem } \\
\text { ini }\end{array}$ \\
\hline
\end{tabular}

\section{Implementasi Sistem}

Pengujian sistem bertujuan untuk melihat apakah sistem yang dirancang sudah sesuai dengan apa yang diharapkan, setelah melakukan pengujian, kualitas sebuah sistem akan terlihat. Berikut tampilan halaman sistemyang telah dirancang mulai daritampilan halaman splash screen, home, halaman tulis data ke dalam tag dan baca data dari tagpada aplikasi android dan halaman login, home, daftar inventory, edit inventory danlaporan pada website.

\section{Tampilan Halaman Splash Screen}

Halaman splash screenadalah tampilan loading pertama kali ketika aplikasi android dijalankan agar terlihat lebih menarik dan terkesan profesional.

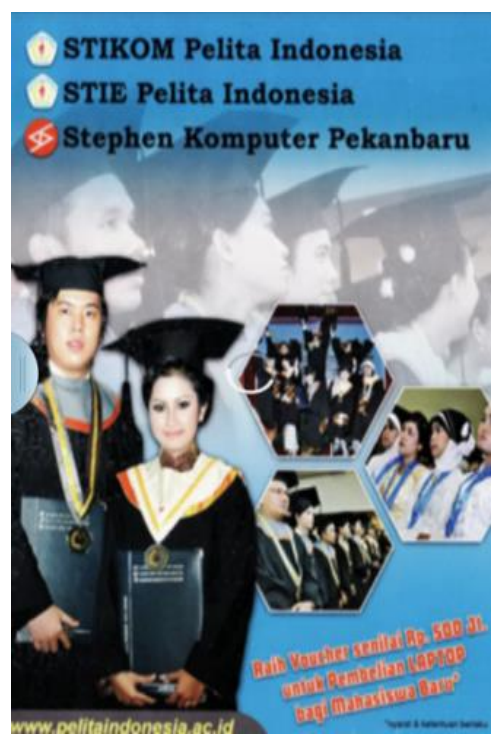

\section{Gambar 3 Tampilan Splash Screen}

Dari gambar diatas terlihat bahwa pada halaman splash screen, yang pada umumnya dibuat untuk menunjukkan logo perusahaan atau logo aplikasi yang dibuat.

\section{Tampilan Halaman Utama}

Halaman ini berisikan tentang menu utama untuk dari aplikasi pelacakan inventory. 


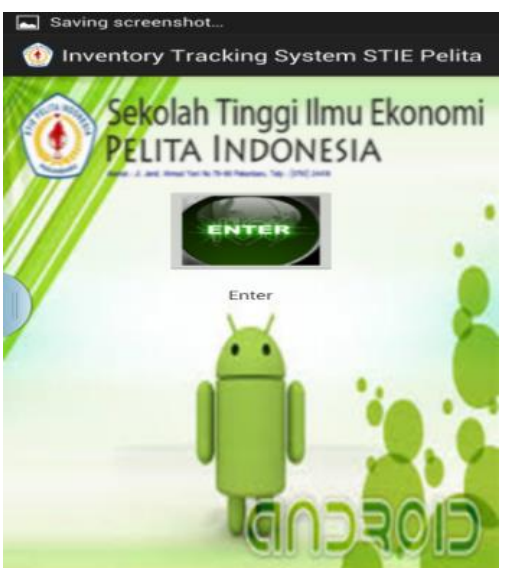

Gambar 4 Tampilan Halaman Utama Aplikasi ITS Android

Dari gambar diatas terlihat proses User harus menekan gambar enter untuk masuk ke halaman tulis data ke NFC tag.

\section{Tampilan form Tulis dan Baca NFC} Tag

Gambar dibawah adalah tampilan formyang akan user isi berupa data-data spesifikasi komputer pada laboratorium yang akan dimasukkan ke dalam NFC tag.

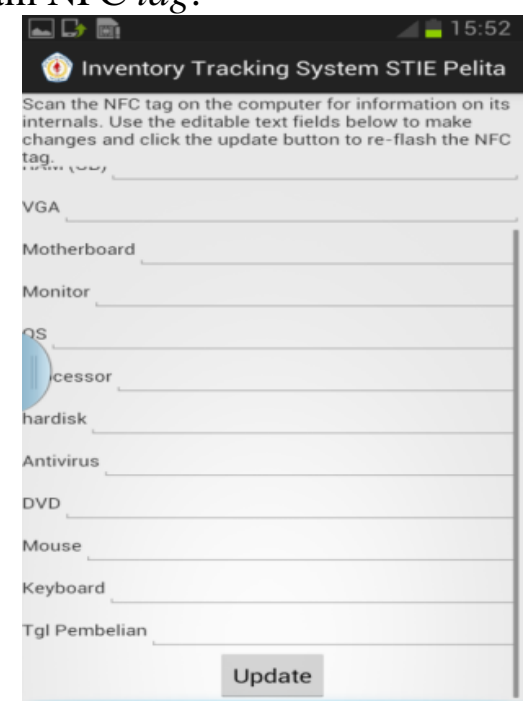

\section{Gambar 5 Tampilan Halaman Form Inventory}

Gambar diatas terlihat bahwa formspesifikasi komponen komputer akan user isi ke dalam NFC tag dan database, kemudian user akan menempelkan smartphone androidnya ke NFC Tag.Berikut tampilan tulis data ke dalam NFC tag seperti gambar dibawah ini :

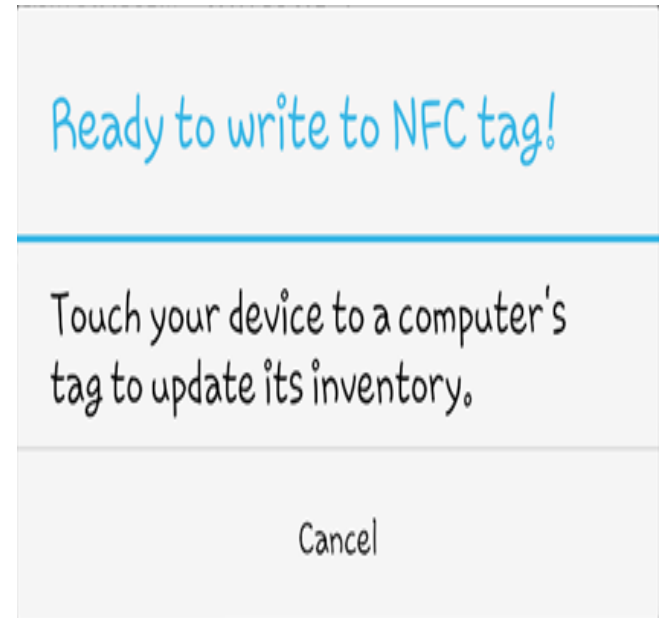

\section{Gambar 6 Tampilan Tulis Data ke Dalam NFC tag}

Kemudian berikut tampilan ketika smartphone android membaca NFC tag ke dalam sistem seperti gambar dibawah ini :

\section{New inventory tag found!}

Read tag and replace currently displayed tag information in the textfields?

No Yes

\section{Gambar 7 Tampilan Baca Data Dari NFC tag}

Tampilan Halaman Login Pada Website

Halaman Login merupakan halaman dimana user memasukkan username dan password agar dapat masuk ke dalam sistem karena halaman login merupakan pintu masuk ke dalam sebuah sistem. Pada gambar 5.6 dibawah ini tampilan halaman login pada sistem ini : 


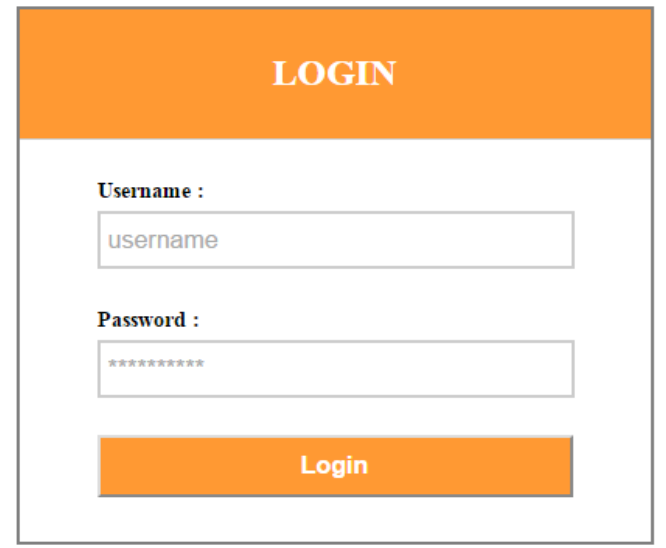

Gambar 8 Tampilan Halaman Login Tampilan Halaman Home Pada Website

Halaman home merupakan halaman utama pada Sistem Pelacakan Inventory STIE PELITA Indonesia yang berisi tentang deskripsi STIE PELITA Indonesia dan juga berisi menu Inventory, laporan dan logout. Berikut dibawah ini tampilan halaman homepada sistem ini :

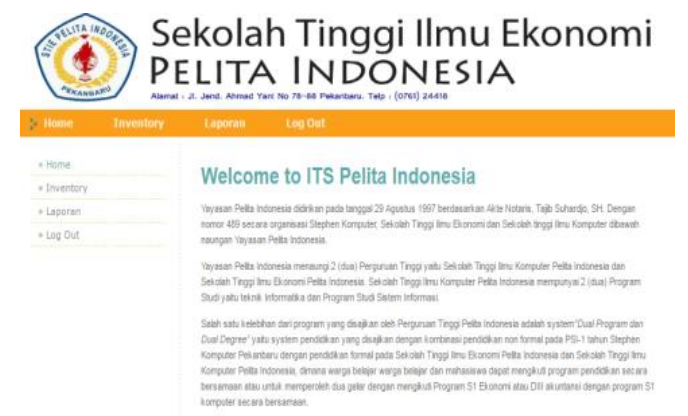

Gambar 9 Tampilan Halaman Home Tampilan Halaman Inventory Pada Website

Halaman inventory ini merupakan daftar dari semua inventory laboratorium komputeryang di input memalui smartphoneandroid yang mana data tersebut dimasukan ke dalam NFC tag juga terinput ke dalam database. Pada halaman ini berisi menu edit untuk mengubah data dan menu delete untuk menghapus inventory.
Dibawah ini merupakan halaman inventory pada Sistem Pelacakan Inventory Lab.Komputer STIE Pelita :

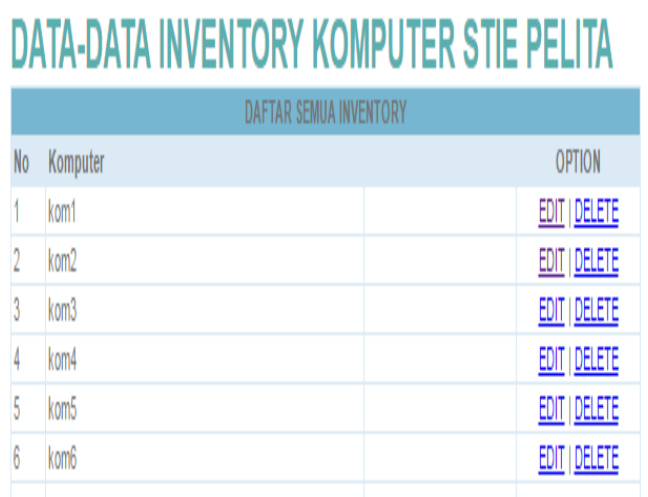

\section{Gambar 10 Tampilan Halaman Inventory}

Tampilan Halaman Laporan Pada Website

Setelah semua data lab.komputer ditulis ke dalam NFC tagdan masuk ke dalam database selanjutnya data diunduh sehingga user bisa melihat tampilan semua inventory lab.komputer yang ada di STIE PELITA Indonesia Pekanbaru.

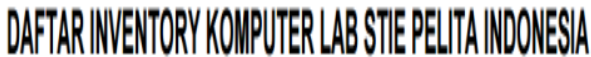

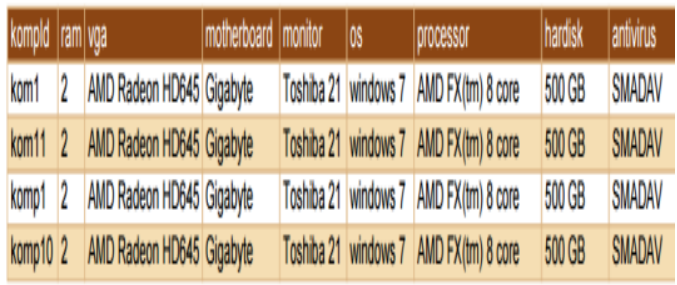

\section{Gambar 11 Tampilan Halaman}

\section{Laporan}

Pengujian program adalah elemen kritis dan jaminan kualitas sistemdan merupakan review akhir dari spesifikasi, perancangan dan pengkodean. Tabel ini diuji dengan tipe black box, yang hanya terfokus pada kebutuhan fungsional perangkat lunak. Berikut beberapa testing yang dilakukan. 
Table 2 BlackBox Testing

\begin{tabular}{|c|c|c|c|c|}
\hline Kasus Uji & $\begin{array}{l}\text { Prosedur } \\
\text { Pengujian }\end{array}$ & $\begin{array}{l}\text { Keluaran } \\
\text { Yang } \\
\text { Diharapkan }\end{array}$ & $\begin{array}{l}\text { Hasi } \\
\text { l }\end{array}$ & Kesimpulan \\
\hline $\begin{array}{l}\text { Buka } \\
\text { Aplikasi } \\
\text { Android }\end{array}$ & $\begin{array}{l}\text { Buka } \\
\text { Aplikasi } \\
\text { mengguna } \\
\text { kan } \\
\text { Smartpho } \\
\text { ne } \\
\text { Android }\end{array}$ & $\begin{array}{l}\text { Tampil } \\
\text { Aplikasi }\end{array}$ & $\checkmark$ & Diterima \\
\hline $\begin{array}{l}\text { Menu } \\
\text { Enter }\end{array}$ & Klik Enter & $\begin{array}{l}\text { Halaman } \\
\text { form } \\
\text { Inventory }\end{array}$ & $\checkmark$ & Diterima \\
\hline Tulis Tag & $\begin{array}{l}\text { Klik } \\
\text { update } \\
\text { dan } \\
\text { tempelkan } \\
\text { smartphon } \\
e \text { ke NFC } \\
\text { tag }\end{array}$ & $\begin{array}{l}\text { Halaman } \\
\text { form } \\
\text { inventory }\end{array}$ & $\checkmark$ & Diterima \\
\hline
\end{tabular}

\begin{tabular}{|c|c|c|c|c|}
\hline Baca Tag & $\begin{array}{l}\text { Tempelka } \\
\mathrm{n} \\
\text { Smartpho } \\
\text { ne ke } \\
\text { NFC tag }\end{array}$ & $\begin{array}{l}\text { Halaman } \\
\text { form } \\
\text { inventory }\end{array}$ & $\checkmark$ & Diterima \\
\hline $\begin{array}{l}\text { Menu } \\
\text { buka } \\
\text { sistem }\end{array}$ & $\begin{array}{l}\text { Buka } \\
\text { website } \\
\text { dengan } \\
\text { mengguna } \\
\text { kan } \\
\text { google } \\
\text { chrome }\end{array}$ & $\begin{array}{l}\text { Tampil } \\
\text { sistem }\end{array}$ & $\checkmark$ & Diterima \\
\hline $\begin{array}{l}\text { Masukha } \\
\text { laman } \\
\text { admin }\end{array}$ & $\begin{array}{l}\text { masukkan } \\
\text { username } \\
\text { dan } \\
\text { password } \\
\text { lalu klik } \\
\text { login }\end{array}$ & $\begin{array}{l}\text { Halaman } \\
\text { Admin }\end{array}$ & $\checkmark$ & Diterima \\
\hline $\begin{array}{l}\text { Masuk } \\
\text { halaman } \\
\text { user }\end{array}$ & $\begin{array}{l}\text { masukkan } \\
\text { username } \\
\text { dan } \\
\text { password } \\
\text { lalu klik } \\
\text { login } \\
\end{array}$ & $\begin{array}{l}\text { Halaman } \\
\text { User }\end{array}$ & $\checkmark$ & Diterima \\
\hline $\begin{array}{l}\text { Menu } \\
\text { inventory }\end{array}$ & $\begin{array}{l}\text { Klik } \\
\text { inventory }\end{array}$ & $\begin{array}{l}\text { Halaman } \\
\text { inventory }\end{array}$ & $\checkmark$ & Diterima \\
\hline $\begin{array}{l}\text { Menu } \\
\text { edit } \\
\text { inventory }\end{array}$ & $\begin{array}{l}\text { Klik edit } \\
\text { inverntory }\end{array}$ & $\begin{array}{l}\text { Halaman } \\
\text { edit } \\
\text { inventory }\end{array}$ & $\checkmark$ & Diterima \\
\hline $\begin{array}{l}\text { Menu } \\
\text { hapus } \\
\text { inventory }\end{array}$ & $\begin{array}{l}\text { Klik } \\
\text { delete } \\
\text { inventory }\end{array}$ & $\begin{array}{l}\text { Halaman } \\
\text { inventory }\end{array}$ & $\checkmark$ & Diterima \\
\hline $\begin{array}{l}\text { Menu } \\
\text { laporan }\end{array}$ & $\begin{array}{l}\text { Klik } \\
\text { laporan }\end{array}$ & $\begin{array}{l}\text { Halaman } \\
\text { laporan }\end{array}$ & $\checkmark$ & Diterima \\
\hline $\begin{array}{l}\text { Menu } \\
\text { logout }\end{array}$ & $\begin{array}{l}\text { Klik } \\
\text { logout }\end{array}$ & $\begin{array}{l}\text { Keluar } \\
\text { Sistem }\end{array}$ & $v$ & Diterima \\
\hline
\end{tabular}

\section{PENUTUP}

Kesimpulan

Dari uraian yang telah dikemukakan sebelumnya maka dapat ditarik beberapa kesimpulan sebagai berikut :

1. Perencanaan dan pemodelan Sistem Pelacakan Inventory memudahkan dalam pengidentifikasian informasi setiap inventory laboratorium komputerdi STIE Pelita Indonesia .

2. Sistem yang dirancang menggunakan NFC pada smartphone android dapat membantu memudahkan user dalam pencapaian suatu informasi agar lebih efektif dan efisien.

Saran

Saran yang dapat diberikan penulis untuk pengembangan selanjutnya yaitu:

1. Penggunaan Teknologi NFC dalam sistem pelacakan inventory yang dipakai dalam pemodelan dan perancangan sistem diatas selanjutnya dapat dikembangkan dan diterapkan pada unit lain di lingkungan STIE Pelita Indonesia Pekanbaru, sehingga dapat diwujudkannya enterprise arsitektur secara keseluruhan dan sempurna.

2. Pemodelan Sistem Pelacakan Inventory menggunakan NFC pada smartphone ini diharapkan dapat dikembangkan menjadi lebih baik lagi.

3. Perlunya sosialisasi lebih lanjut kepada semua stakeholderagar sistem berjalan sesuai dengan harapan dan tujuan.

\section{DAFTAR PUSTAKA}

Finkenzeller K. 2003. Fundamental and Applications in Contactless Smart Cards and Identification. UK: Wiley \& Sons Ltd.

Heene A. danDesmidt S. 2010. Manajemen

Strategik 
Keorganisasian Publik. Bandung: PT RefikaAditama.

Heryanto A., Fuad H. danDananggi D. 2014. Rancang Bangun Sistem Informasi Inventory BarangBerbasis Web Studi Kasus di PT. Infinetworks Global Jakarta. Jakarta.

Juraman S. R.2014.Pemanfaatan Smartphone Android Oleh Mahasiswa Ilmu Komunikasi Dalam Mengakses Informasi Edukatif.

NFC-Forum. 2013. What are the operating modes of NFC devices.[Online]. Available: http://www.nfc-forum.org. (diaksespada 1 Juli 2016).

Rismawati N. 2016. Sistem Absensi Dosen Menggunakan Near Field Communication (NFC) Technology. Fakultas Teknik, Matematika dan Ilmu Pengetahuan Alam.Universitas Indraprasta PGRI.

O'Neill E., Thompson P., Garzonis S. danWarr A. 2007.Reach Out and Touch: Using NFC and 2D Barcodes for Service Discovery and Interaction with Mobile Devices.

Robbins S. dan Coulter M. 2007.Manajemen, Edisi Kedelapan. Jakarta :Penerbit PT Indeks.

Trivedi D.2015.Near Field Communication: Overview and Applications. India. 